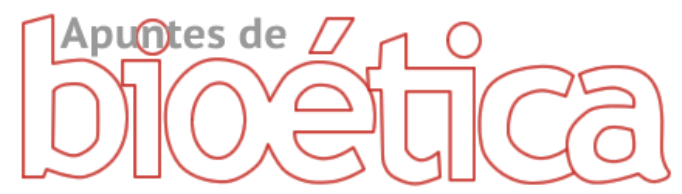

https://doi.org/10.35383/apuntes.v2i2.248

\title{
Aproximación bioética sobre el diagnóstico preimplantacional con fines terapéuticos para terceros
}

\author{
Nataly Cristina Carrasco Salgado ${ }^{1}$
}

INFORMACIÓN DEL ARTÍCULO RESUMEN

\section{Historia del artículo:}

Recibido el 24 de setiembre de 2019

Aceptado el 25 de noviembre de 2019

\section{Palabras claves.}

Diagnóstico preimplantacional

Bebé medicamento

Fines terapéuticos

Reproducción asistida
El artículo realiza una aproximación bioética sobre el Diagnóstico Preimplantacional (DPI) con fines terapéuticos para terceros, procedimiento en el que la persona humana se halla sujeta a múltiples consideraciones que comprometen su desarrollo vital desde su inicio. La reflexión sobre lo dicho, tiene en cuenta aspectos antropológicos, bioéticos y jurídicos.

Bioethical approximation to preimplantation genetic diagnosis for third party therapeutic purposes

\section{ABSTRACT}

\section{Keywords:}

Preimplantation genetic diagnosis

Savior sibling

Therapeutic purposes

Assisted Human Reproduction

This article introduces a bioethical approximation to preimplantation genetic diagnosis (PGD) for third party therapeutic purposes, a procedure in which the human person is subject to several considerations that affect their vital development from their beginnings. This reflection considers anthropological, bioethical and legal aspects. 


\section{Introducción}

El siguiente artículo tiene por objeto establecer un análisis bioético de hechos y circunstancias en torno al diagnóstico preimplantacional (DPI) con fines terapéuticos para terceros, que permitan una aproximación adecuada sobre la materia, especialmente por encontrarse comprometido el desarrollo del ser humano, así como las consideraciones sobre su continuidad.

EI DPI es un procedimiento que permite el análisis de la composición genética de embriones obtenidos mediante fecundación in vitro. Su propósito es identificar aquellos que poseen determinadas características que, dependiendo de la finalidad que se procure, determinan la viabilidad o no de dichos embriones para la implantación.

Entre las posibilidades que ofrece el DPI, está emplearlo con fines terapéuticos para terceros. En este supuesto, el análisis se realiza para identificar la compatibilidad genética entre el embrión estudiado y un tercero, habitualmente un hermano o pariente sanguíneo que padece algún tipo de enfermedad y que requiere para su tratamiento recibir el trasplante de células compatibles.

Estos hechos pueden estudiarse desde diversas disciplinas que proporcionan directrices encaminadas al tratamiento sobre el ser humano. En el siguiente artículo, se abordará la cuestión desde la Biología, Ética y el Derecho, ya que la práctica de estos procedimientos involucra al ser humano desde la generación de su existencia. Asimismo, el artículo tomará como referencia normativa la legislación española y peruana.

Ello, con el propósito de dilucidar aspectos en torno al DPI con fines terapéuticos para terceros, que permitan una aproximación adecuada sobre la persona a partir de una perspectiva bioética y biojurídica.

\section{Metodología}

\section{Sobre el Diagnóstico Preimplantacional (DPI)}

Como antecedentes al DPI con fines terapéuticos para terceros, es importante señalar algunos aspectos conceptuales relativos a éste.

EI DPI se realiza en dos casos: para tratar una enfermedad o para impedir su transmisión. En ese sentido y con evidencias que justifiquen su práctica, mediante el DPI es posible la detección de embriones con enfermedades o anomalías genéticas, pero también la selección de embriones por razones de histocompatibilidad. En este caso se habla de DPI con fines terapéuticos para terceros o DPI extensivo.

Sobre la histocompatibilidad, el trasplante de órganos y tejidos es un procedimiento que, además de la complejidad quirúrgica que implica su realización, requiere considerar fundamentalmente la compatibilidad entre el donante y el receptor. El estudio de compatibilidad, evalúa los antígenos leucocitarios $(H L A)^{2}$ ya que éstos facilitan al sistema inmune determinar la diferencia entre los propios tejidos y los agentes extraños (Fainbom \& Zwirner, 2005, págs. 93-96).

El factor hereditario es fundamental en la determinación de los antígenos HLA que cada persona posee $y$, por lo tanto, un factor

\footnotetext{
2 Son un sistema complejo organizado bajo determinaciones de bases genéticas de donde resultan productos moleculares que son de vital importancia en la regulación inmune, las transfusiones y los trasplantes de órganos y tejidos. Estos genes contribuyen al reconocimiento de los antígenos propios y no propios ante la respuesta inmune a un estímulo antigénico coronado así la respuesta de la inmunidad celular y humoral. Martinez A., J. (2013), Anticuerpos, Antígenos Leucocitarios Humanos y Biomodulares en los Efectos Adversos Agudos de las Transfusiones, Gaceta Médica de México, (149),81-8, p. 83 Obtenido de https://www.anmm.org.mx/GMM/2013/n1/GMM_149_2013_1_081-88.pdf
} 
determinante en el DPI con fines terapéuticos. Ello, ya que es posible realizar procedimientos que sumados a la alteración genética, viabilizan equiparar los antígenos de histocompatibilidad, permitiendo la selección de embriones en óptimas condiciones y además histocompatibles (Carmona C. , 2015, pág. 23).

En ese sentido, es improbable que personas sin ningún parentesco posean la misma estructura de HLA, debido a que "los hijos poseen $50 \%$ del tipo de HLA del padre y de la madre, y entre hermanos el porcentaje de compatibilidad disminuye, siendo solo del $25 \%$. Así, las probabilidades de tener un embrión sano compatible HLA son de 3/16" (Arango, Sánchez, \& Pastor, 2012, pág. 304).

\section{2. ¿Quiénes son los bebés medicamento?}

El desarrollo de las técnicas de reproducción humana asistida, sin duda ha experimentado grandes cambios en la práctica de los procedimientos implicados que, conforme al desarrollo científico y médico, han incorporado métodos que permiten el conocimiento de las características de quien ha sido creado mediante estas técnicas. Es el caso del DPI, cuya finalidad es conocer el estado o condición genética de los embriones obtenidos mediante FIV (fecundación in vitro), hecho que finalmente determinaría su viabilidad para implantación o no.

Dentro de las aplicaciones del DPI, tiene lugar una finalidad que ha generado algunas controversias. Es el caso de los llamados bebés medicamento o saviour sibling -como se les conoce en la literatura angloamericana, que son creados con fines terapéuticos para terceros. La práctica de este procedimiento se remite al año 2000, año en que nace el primer bebé medicamento en el mundo.
Es así como los antecedentes al nacimiento del primer bebé medicamento (véase Aznar en Germán, 2012, pág. 153 y Pinto \& Marcos del Cano, 2016, pág. 251) se remontan al 4 de julio de 1994 con el nacimiento de Molly Nash, hija del matrimonio conformado por Lisa y Jack Nash. La niña padecía anemia de Fanconi (véase Aznar en Germán, 2012 págs 153-155 y Pinto, 2015, pág. 153), enfermedad hereditaria que reduce la producción de hematíes, leucocitos y plaquetas, y que provoca el debilitamiento del organismo causando hemorragias 0 el desarrollo de algún tipo de cáncer, especialmente leucemia.

El tratamiento ideal para combatir dicha enfermedad es un trasplante de tejido hematopoyético $^{3}$ de un donante completamente histocompatible. Para los Nash, la alternativa de concebir un segundo hijo que pudiera ayudar a la niña enferma implicaba el riesgo de que el niño padeciera la misma enfermedad 0 no fuese completamente compatible con ella. Ante dicha circunstancia, en 1996 decidieron iniciar un procedimiento de FIV con DPI.

El procedimiento fue desarrollado por el doctor John Wagner, hematólogo especializado en trasplantes de células extraídas del cordón umbilical, y el doctor Mark Hughes, científico que se encontraba desarrollando un protocolo para examinar la histocompatibilidad de los embriones en el Instituto de Genética Molecular y Humana de la Universidad de Georgetown. Así, Lisa Nash fue sometida a estimulación ovárica y se consiguió la fecundación de algunos embriones, que posteriormente fueron sometidos a DPI para

\footnotetext{
${ }^{3}$ El tejido hematopoyético es el formado por el conjunto de células precursoras de la sangre, formado por tres poblaciones principales: células madre hematopoyéticas, capaces de renovarse a sí mismas, células precursoras comprometidas, responsables de la formación de las distintas estirpes de células sanguíneas y células en maduración, fruto de la diferenciación de las células precursoras. El tejido hematopoyético se localiza en la vida prenatal en el mesénquima extraembrionario, el hígado y el bazo, y en la vida posnatal en la médula ósea.
} 
determinar si padecían anemia de Fanconi, así como la histocompatibilidad con Molly Nash. En ese momento, solo uno de los embriones poseía las características requeridas, por lo que fue implantado. No obstante, a los dieciséis días de transferido, la FIV fracasó.

Años más tarde, en 1999, Lisa Nash volvió a someterse a estimulación hormonal a cargo del doctor Charles Strom del Instituto de Genética Reproductiva de Chicago. En ese momento, se obtuvieron doce ovocitos, que, tras ser fecundados, dieron lugar a dos embriones con HLA idéntico $y$, además, libres de la enfermedad. Lisa Nash quedó embarazada, pero se produjo un aborto $y$, en el segundo intento, el embrión no llegó a implantarse. En el tercer intento, se obtuvieron ocho ovocitos; sin embargo, seis de los embriones resultantes padecían la enfermedad, y finalmente solo uno resultó ser compatible, pero tampoco se logró implantar.

Ante ello, el matrimonio Nash acudió al Centro de Medicina Reproductiva de Colorado a cargo del doctor William B. Schoolcraft y por medio de un nuevo tratamiento hormonal, Lisa Nash produjo veinticuatro ovocitos, de los que, tras ser fecundados, solo uno era compatible con su hija. Nueve días después de la transferencia, se confirmó el embarazo de Lisa Nash. En esta ocasión, para evitar complicaciones y un eventual aborto, Lisa Nash guardó reposo absoluto durante todo el periodo gestacional. Finalmente, el 29 de agosto de 2000, tras más de 50 horas de parto -mediante cesárea-, nació Adam Nash, el primer bebé del mundo seleccionado genéticamente para curar a un hermano enfermo.

Luego del nacimiento de Adam Nash, el 26 de octubre de 2000, el doctor Wagner y sus colaboradores de la Universidad de Minnesota trasplantaron a Molly Nash sangre del cordón umbilical de su hermano y, años más tarde, se expuso mediante evidencias científicas la mejora de su sistema inmunológico. Pese a que no se consiguió curar la enfermedad, el procedimiento logró incrementar la esperanza y calidad de vida de Molly Nash (Pinto \& Marcos del Cano, 2016, pág. 251).

Por su parte, en el contexto iberoamericano, el primer bebé medicamento nacido en España fue Javier Mariscal Puerta, quien nació libre de Beta Talasemia ${ }^{4}$, enfermedad genética que su hermano padecía y que afecta a la producción normal de hemoglobina, ocasionando anemia. El nacimiento se produjo el 12 de octubre de 2008 en el Hospital Virgen del Rocío de Sevilla. El procedimiento se desarrolló en la Unidad de Genética, Reproducción y Medicina Fetal, a cargo del doctor Guilllermo Antiñolo Gil (Carmona M. , 2008).

\section{Cuestiones ético-antropológicas en torno al bebé medicamento}

La posibilidad de cura de una condición congénita, gracias al avance médico y científico en materia reproductiva mediante DPI con fines terapéuticos, precisaría una valoración adecuada de todos los elementos y, sobre todo, de los sujetos implicados durante el desarrollo de estos procedimientos. Ello, fundamentalmente, porque se trata de intervenciones en la persona durante los primeros días de su desarrollo vital.

La práctica médica se encuentra guiada por principios y prerrogativas que, entre otras, tienen por máxima el respeto por la vida y la dignidad de la persona. En ese sentido, el DPI con fines terapéuticos podría incurrir en algunas prácticas éticamente cuestionables.

\footnotetext{
${ }^{4}$ La severidad y tipo de anemia, incluyendo las betas talasemias, dependen de la cantidad de genes afectados. La beta talasemia es causada por mutaciones en la cadena beta de la molécula de hemoglobina.
} 
Al respecto, la valoración de la persona de acuerdo con la dignidad que posee resulta fundamental al abordar el desarrollo vital de ésta, ya que los procedimientos antes mencionados implican manipulación en su primer estado de vida, circunstancia que, al margen de una recta consideración sobre la dignidad de la vida humana, podría propiciar no solo un tratamiento indigno y utilitarista, sino que, además, antijurídico.

\subsection{Dignidad de la vida humana}

La idea de que el ser humano posee un valor superior en relación con los demás seres vivos, es un marco de referencia que, en términos generales, es respetado y garantizado social y jurídicamente. La realidad personal del ser humano permitiría apreciar que éste "aparece dotado de un valor autónomo que impide su relativización radical o su instrumentalización" (Díaz de Terán, 2005, pág. 138); y, por ello, advertir también su naturaleza finalista.

Así, el fundamento de la dignidad humana se encontraría en la propia naturaleza de la persona, que, por ser un rasgo constitutivo radical, exigiría que sea entendida en clave ontológica, es decir, correspondiente al ser mismo de la persona. Por ello, "la operatividad del concepto de dignidad depende de que se reconozca a la persona, a cada una representada en su naturaleza. En caso contrario, el concepto de dignidad resulta estéril, ineficaz, inútil" (González en Díaz de Terán, 2005, pág. 139).

En ese sentido, toda referencia al ser humano debería procurar considerar este especial y radical valor, que, en virtud de su naturaleza, coloca a la persona en otro orden del ser al ostentar cualitativamente una superioridad frente a los demás seres.
EI DPI, probablemente sea uno de los avances científicos más importantes en la materia, ya que permite el manejo de información crucial para el desarrollo de procedimientos médicos según la finalidad que se persiga. El DPI con fines terapéuticos en beneficio de terceros, dados sus componentes, tendría una finalidad altruista al estar destinado al tratamiento y probable cura de alguna enfermedad mediante la donación de tejido hematopoyético del embrión seleccionado. Sin embargo, en este escenario, ihasta qué punto dichos procedimientos, valoran adecuadamente a los embriones implicados conforme a la dignidad y naturaleza finalista que ostentan?

Desde una perspectiva ontológica de la dignidad, "el primer derecho fundamental es el derecho a la vida, ya que su lesión implica la negación radical de la misma dignidad inherente al ser. Todo ataque a una vida humana se traduce en la destrucción misma de la dignidad" (Díaz de Terán, 2005, pág. 90). En ese sentido, el DPI con fines terapéuticos incluye en sus procedimientos la selección embrionaria, que implicaría el descarte de los embriones que no posean las características de histocompatibilidad requeridas. Esta circunstancia supondría una contradicción con la naturaleza finalista de la persona y con la dignidad que esta posee, ya que según sea el caso, son crioconservados, donados o descartados, lo que admitiría su instrumentalización.

En el contexto de la práctica del DPI, lo dicho adquiere relevancia debido a que los procedimientos de selección $y$ experimentación embrionaria contemplarían la licitud ética de sus prácticas en cuanto se sostiene que aún no se trataría de una persona. Ello, ya que durante el desarrollo del proceso de fecundación y de la persona, 
el carácter personal de este individuo en ocasiones es cuestionado, asociándose la personalidad a determinadas funciones que pueda o no ejercer, como la racionalidad, sensibilidad, sociabilidad, entre otras (Palazzani en Ciccone, 2005, pág. 83).

En contraposición a estos argumentos que sostienen que los embriones no son personas, cabe mencionar que la vida humana se inicia con el comienzo del proceso de fecundación y termina con la muerte del individuo. De la unión de los gametos masculino y femenino surge un nuevo ser totalmente distinto e independiente de los gametos que lo generan; por ello "aceptar el hecho de que, después de la fecundación, un nuevo ser humano ha llegado a la existencia ya no es una cuestión de gusto o de opinión. [...] no es una hipótesis metafísica, sino una evidencia experimental" (Léjeune en Ciccone, 2005, pág. 83).

El momento del proceso de fecundación, además de originar el surgimiento de una vida humana, también implicaría la existencia de una persona, puesto que el embrión no solo posee características biológicas que le atribuyen la condición de ser humano, sino que también posee las características que constituyen a un ser como persona humana, características que le atribuyen el ser personal.

Ello, quiere decir que poseería la capacidad de desarrollarse conforme a su naturaleza desde el momento de la fecundación hasta la muerte bajo condiciones naturales. El hecho de que no posea características visibles como independencia, conciencia, e incluso, sensibilidad, no justificarían que no se le considerase persona, ya que, en esa misma línea argumentativa, quienes se encuentren privados de discernimiento, independencia, $y$ sensibilidad por causa de alguna enfermedad u otra circunstancia, tampoco serían considerados como personas.

\subsection{Posible instrumentalización de la persona}

Los avances tecnológicos y científicos en materia médica se orientan a la obtención de resultados calculados y previstos, ya que de este modo se garantiza el éxito de los procedimientos. Esto no supondría ningún conflicto dado que la práctica científica efectivamente requiere exactitud. Sin embargo, cuando dichos procedimientos involucran a la persona, concretamente la manipulación de gametos y embriones ${ }^{5}$, la reflexión sobre la intervención en los procesos naturales de la generación de vida tendría que considerar correctamente cuál es la naturaleza de la persona y por qué a pesar de que la técnica lo permita, existen ciertos límites que deberían ser apreciados.

En ese sentido, en el actual escenario científico y tecnológico en relación con la manipulación de la vida en el DPI con fines terapéuticos, las corrientes utilitaristas, caracterizadas por "hacer prevalecer la bondad del fin buscado sobre el medio utilizado para conseguirlo" (Aznar en Germán, 2012, pág. 160), justifican la instrumentalización de la persona, dejando abierta la posibilidad de comprometer su ser mismo en su radicalidad más absoluta (Andorno, 2012, pág. 68), al determinar la continuidad de su desarrollo conforme a las características genéticas que posee en función de los intereses de terceros.

\footnotetext{
${ }^{5}$ Es conveniente mencionar que la manipulación de gametos no tiene la misma trascendencia ni implicancias éticas que la manipulación de embriones, ello en mérito de la realidad biológica radicalmente distinta entre gametos y embriones, así como de la existencia propia de una persona en el caso de los embriones.
} 
Los desafíos que propone el desarrollo científico requieren una apremiante reflexión antropológica, ya que, según la visión expuesta sobre la constitución del ser humano, sobre todo de su corporalidad, hoy estarían teniendo enfoques reduccionistas, en tanto esta dimensión de la persona admite intervenciones impensables hace algunos años y que considerarían a la persona solo desde el aspecto material de su existencia. En el DPI con fines terapéuticos, el hijo concebido y preseleccionado para el tratamiento de enfermedades genéticas, podría no estar siendo tratado de acuerdo con la dignidad que posee, al ser entendido como un medio que permitiría la consecución del fin perseguido inicialmente, la cura de la enfermedad del tercero, y que no necesariamente coincide con la intención de concebir un hijo sin mediar condición o requerimiento alguno para la continuidad de su desarrollo.

Las circunstancias descritas, también permiten cuestionar si acaso se trata de un nuevo modo de aproximación sobre la vida gracias al avance científico y tecnológico en el ámbito reproductivo, en el que las posibilidades de intervención permitirían el desarrollo o evolución de ciertas condiciones físicas del ser humano, condiciones que, al ser superadas, podrían tener impactos significativos no solo en el ámbito médico sino también económico y social, lo que llevaría a plantearse la licitud de estas acciones, especialmente con el ser humano.

La instrumentalización de la persona, entendida como el tratamiento de un sujeto como un medio u objeto con la finalidad de satisfacer algún interés, sería una consecuencia del DPI con fines terapéuticos para terceros. Debido a que la selección embrionaria estaría motivada por la compatibilidad existente entre el embrión seleccionado y la persona beneficiaria del procedimiento.

La selección embrionaria en los procedimientos de DPI con fines terapéuticos podría incluir en su práctica la ponderación de la compatibilidad genética sobre la realidad completa y compleja de la vida humana. Ya que, a partir del análisis de compatibilidad, se determina si la implantación de embrión examinado es viable o no, en tanto aquellos que son portadores de la enfermedad a tratar en el tercero no serían considerados como viables para implantación $y$, por lo tanto, para continuar su desarrollo vital. En ese sentido, este tipo de acciones serían opuestas a los principios que deberían guiar la práctica médica en primer lugar $y$, sobre todo, en contra del respeto por la vida y la dignidad de la persona.

Por otro lado, en cuanto a los resultados posteriores al DPI con fines terapéuticos, su eficiencia sería cuestionable, ya que las tasas de éxito oscilarían entre 1 y 3\% (Aznar, Lozano, \& Gómez, 2012, pág. $22)^{6}$. Así también, con relación al consentimiento expreso de quien resultaría ser el donante, es decir el embrión, la donación y disposición de sus células y cuerpo se encontrarían a potestad de sus progenitores, ya que el sujeto de la donación sería incapaz de manifestar su consentimiento, por lo que este hecho podría tener una connotación de explotación.

En otro extremo, la calificación como "apropiado" del embrión seleccionado, éticamente representaría uno de los principales problemas, en cuanto esta calificación respondería a criterios

${ }^{6}$ AZNAR, J., LOZANO, J., GOMEZ, I., “¿Es necesaria la producción de bebésmedicamento?", THERAPEIÁ, 4 (2012), p. 22. 
utilitaristas; pese a que, en principio, la evaluación y observación de condiciones o características genéticas mediante DPI no sería éticamente cuestionable en sí misma, ya que la obtención de información genética sobre un embrión podría justificarse de algún modo. Sin embargo, en cuanto esta calificación determinaría las acciones sobre dichos embriones, dentro de las cuales existe la posibilidad de muerte de alguno de ellos, sí merece ser abordada a partir no solo de principios morales, éticos o antropológicos, sino también de las garantías que ofrecen los derechos fundamentales vinculados y plenamente reconocidos por el Derecho (Alvarado \& Santos, 2018); además del problema ético que supone la creación de embriones in vitro.

\section{Cuestiones jurídicas en torno al bebé medicamento}

Sobre el Derecho como marco regulador de la conducta social, éste tiene la función de establecer legislativamente disposiciones que ordenen aspectos jurídicamente relevantes que se vayan suscitando. Es el caso de la reproducción asistida, que conforme los años y el avance científico, ha sido necesario que se establezcan normas que dirijan sus procedimientos, sobre todo por el tipo de intervenciones que realizan sobre el ser humano y cuyo impacto social es considerable. Ahora bien, este aspecto normativo del Derecho no es el único que debe prevalecer sobre las nuevas realidades, sino sobre todo y ante hechos como el mencionado, la reflexión jurídica debe acompañar estas nuevas disposiciones normativas para que el fundamento último del Derecho siempre se encuentre garantizado.

En ese sentido, en el contexto del DPI con fines terapéuticos para terceros, no solo debe considerarse el aspecto científico o biológico especialmente cuando se disponen mecanismos de control legal sobre este tipo de procedimientos- sino, como ya se mencionó, fundamentalmente debería garantizarse el respeto por la persona su integridad y sus derechos fundamentales.

\subsection{El estatuto jurídico del embrión in vitro}

Para la realidad jurídica, existen circunstancias que son relevantes debido al impacto que generan en la composición de los distintos cuerpos normativos que regulan la actividad social. El inicio de la vida humana es una de ellas, ya que, además de las consideraciones científicas o antropológicas en torno a este hecho, para el Derecho constituye un hito que marca el inicio de la protección de la persona por medio de diversos instrumentos jurídicos. A continuación, algunas reflexiones en torno al estatuto jurídico del embrión in vitro tomando como referencia la normativa española.

La protección jurídica de la persona es competencia de los Estados. No obstante, ante el surgimiento de nuevos escenarios relativos a la generación de vida, la cuestión acerca de si los embriones son personas $y$, consecuentemente, sujetos de derecho, es discutida y regulada de diferentes modos.

Es conveniente mencionar conceptualmente quien es considerado como sujeto de derecho, ya que la discusión sobre la personalidad jurídica del embrión $y$, por lo tanto, el alcance de su protecciónparten de ello. Así, un sujeto de derecho es una entidad que además de poseer personalidad -y precisamente gracias a ella-, jurídicamente adquiere el reconocimiento de 
sus capacidades, $y$, por consiguiente, facultan la atribución de derechos y deberes; a diferencia de un objeto de derecho que es una entidad material $o$ inmaterial susceptible de disposición en medio de relaciones jurídicas (Santos en Albaladejo, 1990, págs. 1-2 en Díaz de Terán, 2005, pág. 231).

Al respecto y en el DPI con fines terapéuticos para terceros, el procedimiento implica cierta manipulación en los orígenes de la vida, ya que el análisis genético que permite determinar la compatibilidad con quien será el beneficiario, supone una intervención médica de los embriones in vitro en los primeros días de su existencia, intervención que también representaría una manipulación. Posterior a ello y de acuerdo a los resultados de diagnóstico, la continuidad del desarrollo del embrión en cuestión sería determinada por el personal sanitario o por los progenitores.

La protección del derecho a la vida de los embriones obtenidos por medio de fecundación in vitro y dispuestos para DPI con fines terapéuticos para terceros, no estaría siendo garantizada, ya que los procedimientos implicarían la existencia de más de un embrión para el análisis y posterior implantación -si es que así se determina-, por lo que los embriones que no reúnen las condiciones de compatibilidad requeridas, serían destinados tanto a crioconservación, donación con fines de investigación o, en algún caso, destrucción. Asimismo, jurídicamente la cuestión sobre si los progenitores en el ejercicio de sus facultades podrían determinar la continuidad de la vida de los embriones resultantes del DPI y si estas facultades no se contraponen al derecho a la vida del que el embrión preimplantatorio sería titular, podría ser cuestionable. No obstante, este aspecto se encuentra no solo regulado en la ley, sino que está permitido, por lo tanto, la continuidad de la vida de los embriones resultantes del DPI sobre la decisión de sus progenitores sería legal en el caso de España, por ejemplo.

No solo el derecho a la vida se encuentra comprometido en los procedimientos de reproducción asistida y especialmente en el diagnóstico preimplantacional con fines terapéuticos para terceros, sino que existen más derechos implicados que alcanzan a los demás sujetos de esta práctica médica, tales como los progenitores y la persona quien será receptora de las células obtenidas del llamado bebé medicamento.

\subsection{Principales derechos implicados en el DPI con fines terapéuticos para terceros}

Como ya se mencionó, además del derecho a la vida se encuentran comprometidos en torno al DPI el ejercicio de otros derechos que, según quien demande su satisfacción, adquieren mayor o menor relevancia en las discusiones tanto a nivel jurídico como ético. Sin embargo, no necesariamente todo aquello que se reclamase como derecho realmente lo sería; razón por la cual, determinar los límites de los derechos implicados resulta iluminador en la defensa de quien ostente una posición menos favorecida en las relaciones de justicia.

El derecho a tener hijos es un derecho al que se alude en la práctica de TRHA. Sin embargo, el reconocimiento de dicho derecho no se encuentra literalmente expresado en la mayoría de textos normativos, sino que, por lo general, se le menciona como parte de la interpretación 
de otros derechos vinculados al ejercicio de la sexualidad de la persona (véase Muga González, 2013 y Gómez Sánchez, 1994).

Las circunstancias que motivan la decisión de iniciar procedimientos de reproducción asistida cuya finalidad es conseguir embriones compatibles con acciones destinadas a buscar la cura de un tercero podrían asociarse al ejercicio de este supuesto derecho. Si se tiene por cierto, la pareja o persona que requiere la terapia podría amparar sus requerimientos en este derecho, así como al ejercicio de su vida privada y autodeterminación personal en el aspecto procreativo sin que pueda tener lugar una oposición por parte del Estado. Además, podrían requerir los medios para su satisfacción. Ello, sumado a la regulación específica sobre la materia, revelaría que el hijo procreado con finalidades distintas a su propia existencia posiblemente estaría siendo reducido a la categoría de objeto jurídico. Esta circunstancia se opondría a su individualidad y al amparo jurídico que merecería como persona, bajo una aplicación razonable del derecho y no necesariamente como sucede en el contexto jurídico español.

El desarrollo científico en el ámbito médico permite, desde hace varias décadas, el análisis, estudio y determinación de condiciones de salud desfavorables incluso antes de que la persona nazca. Este desarrollo hoy ha llegado a niveles que hace décadas eran inimaginables y que, además de la detección de enfermedades, permiten la intervención en el proceso del desarrollo vital con finalidades terapéuticas. Sin embargo, ante la idea expuesta en el párrafo anterior, la selección embrionaria admitiría posturas que ya no serían tan drásticas ni reprochables sobre todo cuando se considera la posibilidad de suspender o ponerle fin al desarrollo vital de este ser a causa de sus padecimientos médicos.

Teniendo en cuenta lo expuesto, las facultades personales de autodeterminación relacionadas con el ejercicio de la sexualidad, o del supuesto derecho a tener hijos, sumadas a tratamientos que por medio del DPI con fines terapéuticos para terceros y cuyo éxito es una posibilidad sugerirían que no solo existiría el derecho a tener hijos, sino que este derecho podría también requerir que estos fueran sanos y libres de cualquier condición genética no deseada. Esta circunstancia no se limitaría al DPI con fines terapéuticos, sino que podría presentarse en cualquier procedimiento de fecundación artificial ${ }^{7}$.

Por tanto, las razones que motivarían las posturas a favor de la selección embrionaria en casos de enfermedad en algunos casos responden a la concepción que se tendría de la enfermedad y que, por lo general, está asociada a la calidad de vida, que resultaría ser una especie de parámetro determinado por el bienestar del paciente, asociado a su condición de salud. En este contexto, estaría entendiéndose bajo un criterio absolutizante en el que la calidad de vida sería sinónimo de bienestar, y aquello que se encuentre fuera de este criterio, es calificado de insufrible e, incluso, indigno (Pardo, 2010, págs. 90-91).

En el DPI con fines terapéuticos para terceros, ante la incompatibilidad de los

\footnotetext{
En 2010 en Lima - Perú, Ana María Rodríguez y Walter Gonzales, demandaron por daños y perjuicios a la Clínica Concebir por la suma de S/ $1,000.000$, ya que al someterse a un procedimiento de fecundación in vitro, que tuvo como resultado el nacimiento de mellizas, una de ellas presentaba Síndrome de Down además de afecciones cardiacas congénitas e hipertensión pulmonar, la demandante aludía a una presunta negligencia en los procedimientos y exigía que las condiciones de su hija correspondan a lo que el personal les había garantizado "los mejores embriones: los más vivos los más capacitados". Padre de bebe in vitro: ¿Cómo se sentirá si le dieran un producto fallado? (12 de noviembre de 2010), El Comercio, recuperado de: http://archivo.elcomercio.pe/sociedad/lima/padre-bebe-in-vitro-como-sesentiria-si-le-dieran-producto-fallado-noticia-667840; consultado el 10 de mayo de 2019
} 
embriones que se obtengan $o$ que finalmente el procedimiento no tenga el éxito que se desea, podría plantearse la duda sobre si se estaría afectando en alguna medida el derecho a la salud de este tercero.

Ciertamente la condición clínica del tercero que padece alguna enfermedad grave que precisa la donación de tejido hematopoyético compatible, es un riesgo que pone en peligro su salud $y$, sobre todo, su vida. No obstante, la relación entre la protección de la salud e integridad de las personas se garantiza cuando la afectación de la salud es consecuencia de una omisión $\mathrm{u}$ acción de los poderes públicos, decisiones empresariales 0 del empleador (Pinto Palacios, 2015, pág. 456), de acuerdo a lo señalado en el texto constitucional español. Así, en la situación descrita, la afectación de la salud se origina por una condición genética que da lugar a la enfermedad, por lo que exigir que se respete y garantice el derecho a la salud del tercero enfermo mediante el DPI extensivo, no necesariamente tendría que entenderse como una obligación del Estado.

EI DPI con fines terapéuticos para terceros incluiría el ejercicio de la patria potestad sobre varios sujetos, el hijo que sería el donante, el hijo receptor de la donación de células que posibiliten el tratamiento de su enfermedad; pero además sobre el resto de los embriones creados a lo largo del procedimiento. En ese caso, en cierta medida, sería clara la intención de los progenitores de buscar los medios suficientes que permitan la cura del hijo enfermo, como parte de sus obligaciones; sin embargo, respecto del hijo cuyo nacimiento se encontrase condicionado a la compatibilidad de su composición genética, no necesariamente se observarían adecuadamente las obligaciones que los progenitores tendrían y que procuran el bienestar de este hijo, en tanto podría no ser implantado $y$, en el peor de los casos, descartado. Sin embargo, conforme la normativa vigente, la protección jurídica no aplicaría sino hasta después de ser implantado por lo que, en el supuesto mencionado, la responsabilidad de los progenitores sobre el embrión preimplantatorio no se encuentra bajo ningún marco normativo. Sin embargo, cabe destacar que el respeto por el interés superior del niño en el ejercicio de la autoridad parental debería implicar "actuar en consonancia con la adquisición de sus diversas potencialidades" (Baeza, 2001, págs. 355-362; Rojas, 2009, págs 14-20 en Deza \& Delgado, 2015, pág. 10).

\subsection{Regulación del DPI con fines terapéuticos para terceros en el Perú}

En el Perú, no existe regulación específica sobre procedimientos de reproducción humana asistida, solamente se tiene una referencia a ellos en el artículo 7 de la Ley General de Salud que dispone lo siguiente: "Toda persona tiene derecho a recurrir al tratamiento de su infertilidad, así como a procrear mediante el uso de técnicas de reproducción asistida, siempre que la condición de madre genética y de madre gestante recaiga sobre la misma persona. Para la aplicación de técnicas de reproducción asistida, se requiere del consentimiento previo y por escrito de los padres biológicos. Está prohibida la fecundación de óvulos humanos con fines distintos a la procreación, así como la clonación de seres humanos" (Ley No 26842 - Ley General de Salud, 1997).

Siendo que no existe regulación en la materia que detalle el desarrollo de TRHA, consecuentemente tampoco existen 
disposiciones específicas sobre el DPI, y mucho menos sobre el DPI con fines terapéuticos para terceros. Sin embargo, pese a este vacío legal, en la realidad dichos procedimientos sí tienen lugar, quedando fuera del control y supervisión que el Estado debería ejecutar.

Sobre la donación de tejidos, existe la Ley General de Donación de Órganos y/o Tejidos Humanos que, si bien tiene la finalidad de favorecer o mejorar sustancialmente la salud o calidad de vida de otra persona, tampoco contempla de manera específica regulación alguna sobre el DPI con fines terapéuticos para terceros. Los supuestos en los que podría encontrarse previsto, solamente se refieren a la donación de tejidos regenerables por parte de donantes vivos; así, el articulo 9.1 menciona: "Los menores de edad o incapaces pueden ser donantes siempre que los padres o tutores otorguen la autorización correspondiente y no perjudiquen la salud o reduzcan sensiblemente el tiempo de vida del donante" ( Ley N 28189 - Ley General de Donación de Órganos y/o Tejidos Humanos, 2004).

No obstante, en el texto del Decreto Supremo $N^{\circ}$ 013-2001-SA mediante el que se crea el Consejo Nacional de Bioética, se menciona en el primer considerando "Que los derechos y el bienestar de los seres humanos que participen como sujetos de experimentación en proyectos de investigación científica en sus diversas etapas, deben ser protegidos, observándose los principios éticos, bioéticos y deontológicos". Asimismo, ante el desarrollo científico en materia biomédica, en el año 2002 se incorporó al Código Penal, el capítulo V, referido a los delitos de manipulación genética; así el artículo 324 del Código Penal regula: "Toda persona que haga uso de cualquier técnica de manipulación genética con la finalidad de clonar seres humanos, será reprimido con pena privativa de la libertad no menor de seis ni mayor de ocho años e inhabilitación [...]"; sin embargo, como se aprecia, la referencia de dicho artículo es exclusiva a los procedimientos de clonación de seres humanos.

Estas disposiciones normativas evidencian una intención de garantizar los derechos y el respeto de la persona en todas las etapas de su vida. No obstante, por sí mismos resultarían insuficientes ya que solamente evidencian la postura del Estado frente a circunstancias que implican la manipulación de la persona, más la ausencia de regulación específica hace que estas disposiciones sean infructuosas, especialmente teniendo en cuenta que dichos procedimientos se realizan habitualmente en clínicas y centros especializados en el Perú sin que exista algún tipo de fiscalización o control sobre sus prácticas.

Por su parte y en concordancia con la protección constitucional que la vida posee conforme al artículo 2 de la Constitución Política del Perú, resulta claro el vacío legal en torno a la reproducción humana asistida así como los procedimientos derivados y que tendría como consecuencia situar al concebido en una situación de desprotección jurídica que lejos de no tener lugar ante la ausencia de regulación, ciertamente sucede sin algún tipo de control o regulación que este destinada a garantizar los derechos de los sujetos involucrados.

\section{Conclusiones}

$>$ La vida humana es un proceso continuo que se desarrolla paulatinamente desde el 
momento de la concepción. Este proceso es idéntico tanto en los embriones concebidos in vivo como in vitro.

El desarrollo científico en reproducción asistida ha tenido una evolución constante y sorprendente en los últimos años. Mediante los procedimientos de diagnóstico es posible determinar cuáles son las características genéticas que los embriones preimplantatorios poseen $y$, dependiendo de la finalidad que se persiga, se determina también la continuidad de su desarrollo vital. Este diagnóstico previo a la implantación se emplea entre otros fines, para conseguir embriones compatibles con un tercero, que por lo general se trata de un hermano o pariente sanguíneo, que padece de alguna enfermedad genética que compromete su vida y que requiere ser tratada mediante el trasplante de células compatibles y que facilitarían la cura 0 el tratamiento de estas condiciones genéticas. Sin embargo, el tratamiento que los embriones preimplantatorios reciben durante esta etapa de diagnóstico, implica una selección que responde al fin que se persigue y que sitúa a aquellos embriones no compatibles en una posición que compromete drásticamente la continuidad de su desarrollo, ya que son destinados a crioconservación, experimentación o destrucción.

En cuanto al carácter personal del ser humano, este ha sido también cuestionado en mérito a las limitaciones propias de la etapa inicial del desarrollo embrionario, en tanto al no poseer características que evidencian una completa autonomía o encuentren completamente definida su constitución, no podrían ser considerados personas. Este argumento resulta muy conveniente en la discusión sobre la licitud de las intervenciones sobre la vida humana, debido a que, si los embriones preimplantatorios no poseen personalidad, no serían susceptibles de protección jurídica.

$>$ Al respecto, es cierto que los embriones preimplantatorios encuentran muchas de sus capacidades limitadas a su propio estado de desarrollo vital, pero ello no implica que por no ver ejercitadas dichas capacidades no tengan que ser considerados personas. A lo largo del desarrollo vital del ser humano -que como ya se apuntó es constante desde la concepción hasta la muerte- muchas de sus capacidades se encuentran suspendidas por diversas circunstancias. Por ello, la imposibilidad de ejercitar todas sus potencias no lo hace menos persona y más bien si, por la condición en la que se encuentra, requiere mucha más protección, precisamente para garantizarse la continuidad de su desarrollo.

Uno de los argumentos a favor del DPI con fines terapéuticos para terceros es el carácter altruista que tendría, en tanto se desarrolla persiguiendo la cura de un tercero que encuentra su vida en un riesgo considerable. Sin embargo y sin perjuicio de ello, existen circunstancias que deben ser observadas bajo un amplio criterio que tenga en cuenta a todos los sujetos involucrados, así como que procure el respeto $y$ trato correspondiente a la dignidad que toda persona ostenta. Es en ese sentido que, aunque el DPI extensivo busque facilitar un tratamiento médico, indudablemente se somete a los embriones parte del proceso a tratos que son contrarios a su dignidad y que adquieren matices utilitaristas y eugenésicos. 
El Derecho, en concordancia con sus fundamentos y los principios que dirigen su práctica, debería garantizar el respeto por la persona desde el origen de esta. Sin embargo, conforme el desarrollo social -que ciertamente exige que la ciencia jurídica acompañe la realidad mediante disposiciones normativas alineadas a la búsqueda del bien común y a la práctica de la justicia- en lugar de brindar garantías mediante el aparato jurídico, se emplea para legitimar conductas que desconocen la realidad del ser humano y que lo colocan en una situación de indefensión especialmente en el inicio de su desarrollo vital. EI DPI extensivo encuentra regulada su práctica conforme a disposiciones legislativas que establecen los términos en los que su aplicación se realizará. No obstante, este marco normativo que permite su desarrollo no reviste de la protección jurídica que merecen los embriones sometidos a estos procedimientos, y más bien mediante diversos pronunciamientos de relevancia jurídica, establecen una clara postura sobre la categoría jurídica en la que se encuentran situados.

La actividad del jurista debe estar orientada no solo a proporcionar herramientas o medios que ordenen el desarrollo social, sino también a la reflexión jurídica. Mediante esta, es posible la atribución y protección apropiada de derechos y deberes, así como de establecer los límites que implica su ejercicio. Hoy, en mérito a la libertad y a la autonomía, se pretende revestir de contenido jurídico aquello que se desea y convertir estos deseos e intereses en exigibles frente a los demás. En ese sentido, la labor del jurista es fundamental en tanto no todo aquello que se exige como derecho lo es, y es mediante la intervención de este que es posible brindarle categoría jurídica a aquello que realmente lo es, procurando ante todo el respeto por la persona de manera integral.

DI DPI con fines terapéuticos para terceros se ha convertido en una práctica susceptible de cuestionamientos de diversa índole, ya que confluyen intereses que, por el contenido social e incluso emotivo que poseen, pueden enfrentarse a la adecuada valoración que la vida merece. Esta valoración implica el respeto por la vida desde el inicio de su desarrollo y que no debe estar condicionada a criterios que permiten procesos de selección y descarte que solamente propician, además de vulneraciones de derechos de sujetos claramente en situación de desventaja, un camino hacia una sociedad más permisiva y deshumanizada.

\section{Bibliografía}

Alvarado, J. T., \& Santos, M. (2018). Ethical Problems with the Preimplantation Genetic Diagnosis of Human Embryos. Acta Bioethica, 24(1), 75-83.

Andorno, R. (2012). Bioética y dignidad de la persona. Madrid: Tecnos.

Arango, P., Sánchez, P., \& Pastor, L. (2012). Diagnóstico genético preimplantatorio y el 'bebe medicamento': Criterios éticos encontrados en la literatura biomédica y bioética. Cuadernos de Bioética, XXII/(2), 304.

Aznar, J. (2012). Bebé medicamento, aspectos médicos, sociológicos y éticos. En $\mathrm{R}$. Germán Zurriaráin, La desprotección del 
no nacido en el siglo XXI. Madrid: Ediciones Internacionales Universitarias.

Aznar, J., Lozano, J., \& Gómez, I. (2012). ¿Es necesaria la producción de bebésmedicamento? THERAPEÍA(4), 13-25.

Baeza Concha, G. (2001). El interés superior del niño: Derecho de rango constitucional, su recepción en la legislación nacional y aplicación en la jurisprudencia. Revista Chilena de Derecho, 28(2), 355-362.

Carmona, C. (2015). Diagnóstico genético preimplantacional: Revisión de la metodología y aplicaciones clínicas actuales. Recuperado el 12 de abril de 2018 de https://riunet.upv.es/bitstream/handle/102 51/56317/CARMONA\%20-

$\% 20$ Diagnóstico\%20genético\%20preimpl antacional\%20\%28DGP\%29\%3A\%20Revi sión\%20de\%20la\%20metodolog\%C3\%A Da\%20y\%20de\%20las\%20aplic....pdf?seq uence $=5 \&$ isAllowed $=y$

Carmona, M. (15 de diciembre de 2008). Nace el primer "bebé medicamento» español, concebido para salvar a su hermano enfermo. Obtenido de https://www.abc.es/20081015/nacionalsociedad/nace-primer-bebemedicamento-20081015.html

Ciccone, L. (2005). Bioética, historia, principios, cuestiones. Madrid: Palabra.

Deza Huaman, R. d., \& Delgado Villena, C. A. (2015). El uso de los bebés medicamento a través de la donación: Aspectos éticosjurídicos.
Díaz de Terán, M. C. (2005). Derecho y nueva eugenesia. Pamplona: Eunsa.

Fainbom, L., \& Zwirner, N. W. (2005). Estructura y función del complejo mayor de histocompatibilidad. En L. Fainboim, \& J. Geffner, Introducción a la Inmunología Humana (págs. 93-96). Buenos Aires: Editorial Médica Panamericana.

Germán Zurriaráin, R. (2012). La desprotección del no nacido en el siglo XXI. Madrid: Ediciones Internacionales Universitarias.

Gómez Sánchez, Y. (1994). El derecho a la reproducción humana. Madrid: Marcial Pons.

Igareda, N. (2011). "El hipotético derecho a la reproducción". Cuadernos Electrónicos de Filosofía del Derecho(23), 252-271.

Ley No 26842 - Ley General de Salud. (15 de julio de 1997). Lima: Diario Oficial El Peruano.

Ley $N^{\circ} 28189$ - Ley General de Donación de Órganos y/o Tejidos Humanos. (16 de marzo de 2004). Lima: Diario Oficial El Peruano.

Martínez, J. C. (2013). Anticuerpos, antígenos leucocitarios humanos y biomoduladores en los efectos adversos agudos de las transfusiones. Gaceta Médica de México(149), 81-88. Obtenido de https://www.anmm.org.mx/GMM/2013/n 1/GMM_149_2013_1_081-088.pdf

Muga González, R. (2013). El denominado derecho a procrear y la dignidad de la persona humana como presupuesto de todo derecho. Revista IUS, II/(6), 1-22. 
Pardo, A. (2010). Cuestiones Básicas de Bioética. Madrid: Rialp.

Pinto Palacios, F. (2015). Nacidos para salvar: Un análisis ético-jurídico del "bebé medicamento".
Pinto Palacios, F., \& Marcos del Cano, A. (2016). Bebé medicamento, protección de la salud y sistema sanitario público: Una reflexión desde el principio de justicia. Universitas(24), 243-265. 